\title{
Influence of constant strain on the elasticity of thermoplastic orthodontic materials
}

\author{
Sayuri INOUEE ${ }^{1,2}$, Satoshi YAMAGUCHI ${ }^{1}$, Hiroshi UYAMA ${ }^{3}$, Takashi YAMASHIRO² and Satoshi IMAZATO1,4 \\ ${ }^{1}$ Department of Biomaterials Science, Osaka University Graduate School of Dentistry, 1-8 Yamadaoka, Suita, Osaka 565-0871, Japan \\ ${ }^{2}$ Department of Orthodontics and Dentofacial Orthopedics, Osaka University Graduate School of Dentistry, 1-8 Yamadaoka, Suita, Osaka 565-0871, \\ Japan \\ ${ }^{3}$ Division of Applied Chemistry, Osaka University Graduate School of Engineering, 2-1 Yamadaoka, Suita, Osaka 565-0871, Japan \\ ${ }^{4}$ Department of Advanced Functional Materials Science, Osaka University Graduate School of Dentistry, 1-8 Yamadaoka, Suita, Osaka 565-0871, \\ Japan \\ Corresponding author, Satoshi YAMAGUCHI; E-mail: yamagu@dent.osaka-u.ac.jp
}

\begin{abstract}
The aim of this study was to identify a physical property suitable for evaluating the orthodontic force by analyzing the physical properties of thermoplastic materials. Four thermoplastic materials were used: Essix A $+{ }^{\circledR}$ Plastic (EA), DURAN ${ }^{\circledR}$ (DU), Erkodur (ER), and Essix $\mathrm{C}+{ }^{\circledR}$ Plastic (EC). Finite element analysis (FEA), a water absorption test, constant strain loading test, X-ray diffraction (XRD) and Fourier transformation infrared spectroscopy analysis were conducted. FEA found a significant correlation between the elastic modulus and the orthodontic force. The water absorption of EC was significantly smaller than the other materials. EC showed no elastic modulus change. The XRD pattern indicated that EC was a crystalline polymer. FEA of thermoplastics showed that the elastic modulus is suitable for the evaluation of orthodontic force. The crystalline thermoplastic EC demonstrated a stable elastic modulus even under strain in a wet environment, suggesting the advantage of its use as an orthodontic aligner material.
\end{abstract}

Keywords: Thermoplastics, Aligner, Orthodontic force, Elastic modulus

\section{INTRODUCTION}

In recent years, aesthetic requirements for orthodontic treatments and the use of transparent aligners in orthodontic treatments have increased ${ }^{1)}$. An aligner device was developed in the early 1970 s as a retainer to keep the teeth in an aligned position after orthodontic treatment. Thereafter, a method for using aligner devices to move the teeth was proposed ${ }^{2}$. A split plaster dental model fixed with wax was used as a setup model and each tooth was positioned so the aligned position could be determined by a dentist. To create the aligner device thermoplastic materials were heated, softened, and vacuumed on the setup model using a pressure forming machine. This aligner device has been used for partial movement of less than two teeth in one dental arch within $1.0 \mathrm{~mm}^{2)}$ and thermoplastic materials with various compositions and thicknesses have been tested for effective orthodontic treatment ${ }^{3-5)}$. An aligner device manufacturing method using a digital setup model designed by simulating tooth movement in silico has been proposed ${ }^{6,7)}$. Since the setup model was fabricated with a three-dimensional (3D) printer, the aligner device was accurately and easily manufactured compared with the conventional split plaster model method, which requires manual operation. Furthermore, analysis of the force direction required for the tooth movement and adjustment of the amount of tooth movement by bonding an attachment to the tooth surface were determined for

Color figures can be viewed in the online issue, which is available at J-STAGE.

Received Apr 11, 2019: Accepted May 29, 2019

doi:10.4012/dmj.2019-104 JOI JST.JSTAGE/dmj/2019-104 the correct force loading in an optimal direction ${ }^{8,9}$. Thus, at present, treatment using thermoplastic orthodontic appliances has been expanded from minor tooth movement to whole teeth orthodontic treatment ${ }^{10-13)}$.

However, the amount of tooth movement within one aligner was limited to the range of $0.25-1.0 \mathrm{~mm}$ and it depended on the compositions and thicknesses of the thermoplastic materials ${ }^{3,14}$. Also, after setting the aligner on dentition, the tooth is immediately subjected to a large orthodontic force that decreases significantly over time ${ }^{15}$. Therefore, in the current treatment system, the aligner must be replaced every $10-14$ days and about 50 aligners may be required for the whole teeth orthodontic treatment. For effective orthodontic treatment with aligners, thermoplastic materials able to constantly exert an orthodontic force suitable for tooth movement are required.

To investigate aligner orthodontic devices formed from thermoplastic materials, the optimal composition of the physical properties of the thermoplastic materials must be determined and they must be extremely effective in vitro without the measurement of the orthodontic force. However, there have only been a few studies of the physical properties of the thermoplastic orthodontic materials ${ }^{4,16-20)}$ and the orthodontic force exerted by the aligner $^{21-25)}$. There has been no study to investigate the relationship between the behavior of the orthodontic force exerted by the aligner and the change in the physical properties of the thermoplastic materials over a two week period.

The aim of this study was to identify a physical 
property suitable for evaluation of the orthodontic force from an analysis of the physical properties of commercially available thermoplastic materials and to find the factors that influence the physical properties of thermoplastic materials.

\section{MATERIALS AND METHODS}

\section{Specimen preparation}

Four commercial thermoplastic materials were used: Essix A+ ${ }^{\circledR}$ Plastic (EA; DENTSPLY Raintree Essix, Sarasota, FL, USA), DURAN ${ }^{\circledR}$ (DU; Scheu Dental, Iserlohn, Germany), Erkodur (ER; ERKODENT Erich Kopp, Pfalzgrafenweiler, Germany), and Essix $\mathrm{C}+{ }^{\circledR}$ Plastic (EC; DENTSPLY Raintree Essix). All of these materials were $1.0 \mathrm{~mm}$ thick single-layer materials. The detailed composition of each material is shown in Table 1.

Physical property test and $3 D$ finite element analysis (FEA)

According to ISO 527-2 $2^{26)}$, type 5B specimens which a thickness of $1.0 \mathrm{~mm}$ (Fig. 1a) were prepared with each material and the dried specimens were weighed. The volume of the sample was measured by a dry density meter (Accupic II 1340, Shimadzu, Kyoto, Japan). The density was calculated by dividing the measured weight by the volume $(n=5)$. Tensile tests were conducted using a compact universal testing machine with a $500 \mathrm{~N}$ load cell (EZ-SX, Shimadzu), and the elastic modulus was determined from the slope of the obtained stress-strain curve $(n=5)$.

According to ISO 527-327), type 2 specimens with a thickness of $1.0 \mathrm{~mm}$ (Fig. 1b) were prepared with each material, and the Poisson's ratio was measured using a universal material testing machine with a $30 \mathrm{kN}$ load cell (5582, Instron, Norwood, MA, USA) $(n=3)$. Strain gauge (KFG-5-120-C1-23, Kyowa, Tokyo, Japan) was attached on the surface of the specimens by using soft adhesives to measure the vertical strain $\varepsilon_{v}$ and horizontal strain $\varepsilon_{h}$ (Fig 1b). Poisson's ratio $\mu$ was obtained by following equation.

$$
\mu=\frac{\varepsilon_{h}}{\varepsilon_{v}}
$$

Using CAD software (SolidWorks Simulation 2011, Dassault Systèmes Solidworks, Waltham, MA, USA), a model of the maxillary central incisors and right lateral incisor based on a $3 \mathrm{D}$ organ model $^{28)}$ with $0.25 \mathrm{~mm}$ periodontal ligament was created, and a $1.0 \mathrm{~mm}$ thick thermoplastic orthodontic appliance was mounted on the incisors (Fig. 2). The center of rotation was defined on the middle of the root and the maxillary right central incisor was tipped $1^{\circ}$ to the labial. Orthodontic force was calculated based on each material's density, elastic modulus, and Poisson's ratio with 3D FEA.

\section{Water absorption test}

Twenty round specimens, $\varphi 15 \pm 0.1 \mathrm{~mm} \times 1.0 \pm 0.1 \mathrm{~mm}$, of
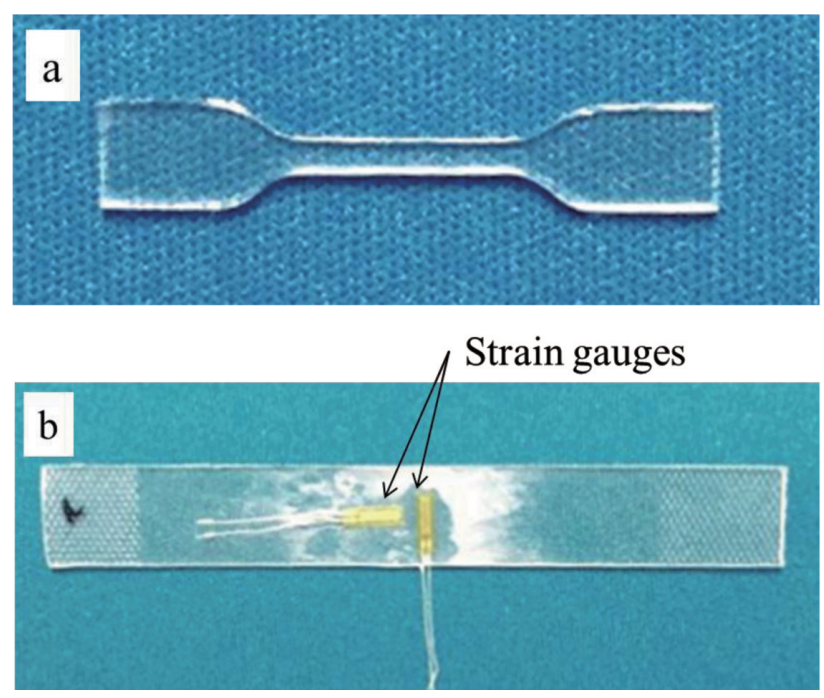

Fig. 1 Specimens used for testing: a) type $5 \mathrm{~B}$ specimen to measure the elastic modulus (1.0 $\mathrm{mm}$ thick), and b) type 2 specimen to measure Poisson's ratio (1.0 mm thick).

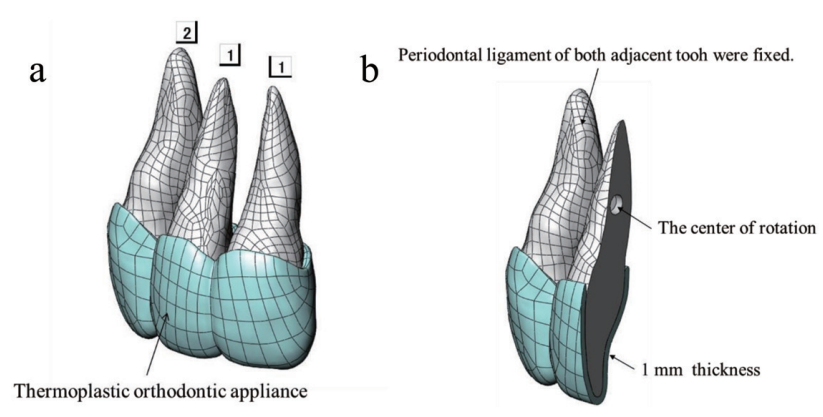

Fig. 2 a) CAD model used for 3D FEA. b) Cross section of CAD model and boundary conditions for 3D FEA.

Table 1 Orthodontic thermoplastic materials used in this study

\begin{tabular}{lcll}
\hline \multicolumn{1}{c}{ Product } & Code & \multicolumn{1}{c}{ Manufacturer } & \multicolumn{1}{c}{ Category/Composition } \\
\hline Essix A+Plastic & EA & DENTSPLY Raintree Essix & Polyester (PES) \\
Duran & DU & Scheu Dental & Polyethylene terephthalate glycol (PETG) \\
Erkodur & ER & Erkodent Erich Kopp & PETG \\
Essix C+Plastic & EC & DENTSPLY Raintree Essix & Polypropylene (PP) \\
\hline
\end{tabular}


each material were prepared according to ISO $4049^{29)}$. The specimens were stored in a desiccator at $37 \pm 1^{\circ} \mathrm{C}$ for $22 \mathrm{~h}$. The specimens were moved to another desiccator at $23 \pm 2{ }^{\circ} \mathrm{C}$. After $2 \mathrm{~h}$, the specimen was taken out and weighed with an accuracy of $0.1 \mathrm{mg}$. This cycle was repeated until a constant weight $\left(m_{1}\right)$ was achieved. After final drying, the volume $(V)$ was measured using a dry density meter (AccuPyc II 1340). The specimen was placed vertically and soaked in water at $37 \pm 1^{\circ} \mathrm{C}$. After 7 days and 14 days, the specimen was taken out and washed with distilled water, and the adhered water on the surface of the specimen was removed using paper. The specimens were swung in the air for $15 \mathrm{~s}$ and weighed 1 min after being taken out of the water $\left(m_{2}\right)$. Using the same drying method, we again achieved a constant weight $\left(m_{3}\right)$. Water absorption $\left(W_{s p}\right)$ was obtained for each of the specimens using the following equation:

$$
W_{s p}=\frac{\left(m_{2}-m_{3}\right)}{V}
$$

\section{Constant strain loading test}

From each material, 15 specimens of $1.0 \mathrm{~mm}$ thickness were prepared according to ISO 527-2 type 5B. A portion of the specimens were immersed in distilled water at $37^{\circ} \mathrm{C}$ with no strain for $24 \mathrm{~h}$ and 2 weeks $(n=5)$. The remaining specimens were loaded to $1 \%$ strain with an original loading device (Fig. 3) and were stored in distilled water at $37^{\circ} \mathrm{C}$ for 2 weeks $(n=5)$. To determine the elastic moduli of the materials, tensile tests were conducted with the compact universal testing machine (EZ-SX, Shimadzu).

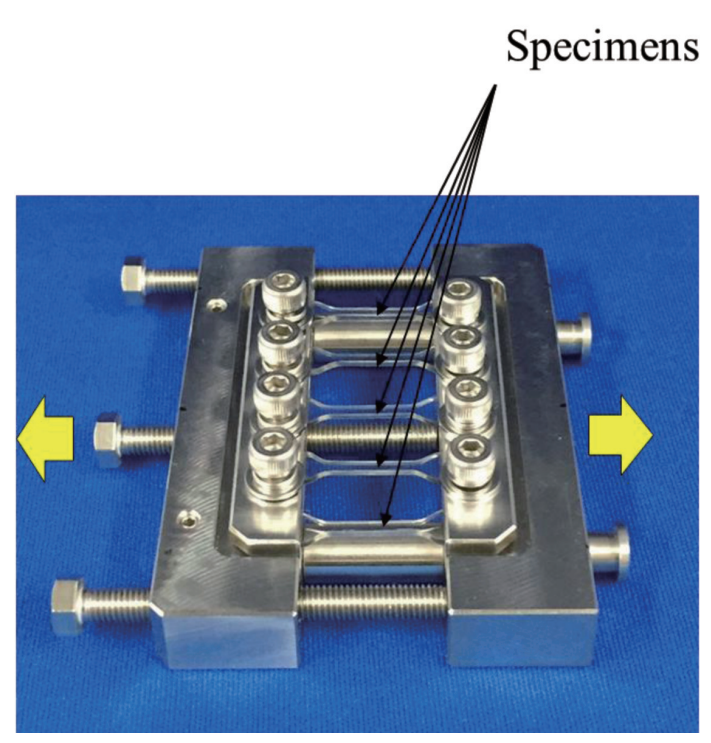

Fig. 3 Device designed to apply strain loading. One percent strain was applied by pulling both sides of the specimens (yellow allows). To avoid slip between the specimen and gripper, a micro concavo-convex shape was added on the surface of the gripper by laser machining.

\section{$X$-ray diffraction analysis}

Test specimens were prepared similar to the water absorption test and subjected to XRD analysis (Rint2000, Rigaku, Tokyo, Japan) in dry condition to examine the crystallinity of each material. This analysis was conducted at $2 \theta$ range between $2^{\circ}$ and $60^{\circ}$ with a step size of $0.02^{\circ}$ in a continuous mode of $4.0^{\circ} / \mathrm{min}$.

\section{Fourier transformation infrared spectroscopy (FT-IR) analysis}

To investigate the molecular structure of each material, FT-IR was conducted. Part of each material $(6.0 \times 6.0 \times 1.0$ $\mathrm{mm})$ was prepared and the spectra were recorded with an FT-IR spectrometer (FT-IR 8300, Shimadzu) and averaged over 20 scans between $700-4,000 \mathrm{~cm}^{-1}$.

\section{Statistical analysis}

Mean density, elastic modulus, and Poisson's ratio obtained from physical property tests were analyzed by one-way analysis of variance (ANOVA) and Scheffe's tests with $p$-values less than 0.05 were considered statistically significant. These measurements and the orthodontic force obtained from FEA were analyzed by Spearman's correlation tests (PASW Statistics 18, IBM, Somers, NY, USA) and $p$-values less than 0.01 were considered statistically significant.

The mean amount of water absorption of EA, DU, $\mathrm{ER}$, and EC after $24 \mathrm{~h}$ and 2 weeks were analyzed by two-way ANOVA and Bonferroni tests (PASW Statistics 18). The mean elastic modulus of EA, DU, ER, and EC were analyzed by Student's $t$-test (PASW Statistics 18). $p$-Values less than 0.05 were considered statistically significant for both values.

\section{RESULTS}

\section{Physical properties and orthodontic forces}

Table 2 shows the results of the physical property tests and orthodontic forces obtained by 3D FEA. In Fig. 4, the horizontal axis is each physical property value and the vertical axis is the obtained orthodontic correction force. The correlation coefficients between density (Fig. 4a), modulus of elasticity (Fig. 4b), and Poisson's ratio (Fig. 4c) and correction force were 0.800, 1.000, and -0.316 , respectively, and a significant correlation was found only for the elastic modulus.

Water absorbability of thermoplastic orthodontic materials The amount of water absorption is shown in Fig. 5. The water absorption of EA, DU, ER, and EC after $24 \mathrm{~h}$ was $8.300 \pm 0.1148,8.513 \pm 0.2690,6.958 \pm 0.2259$, and $0.1086 \pm 0.4044 \mu \mathrm{g} / \mathrm{mm}^{3}$, respectively. EC had a significantly smaller water absorption than the other materials. The water absorption after 2 weeks was $11.51 \pm 0.3283 \mu \mathrm{g} / \mathrm{mm}^{3}$ in EA, $11.83 \pm 0.2586 \mu \mathrm{g} / \mathrm{mm}^{3}$ in DU, $9.809 \pm 0.2153 \mu \mathrm{g} / \mathrm{mm}^{3}$ in ER, and $0.8655 \pm 0.7568 \mu \mathrm{g} / \mathrm{mm}^{3}$ in EC, which was significantly higher in all materials than after $24 \mathrm{~h}$. However, the water absorption of EC was significantly smaller than other materials. 
Table 2 Physical properties and orthodontic force of each thermoplastic materials

\begin{tabular}{ccccc}
\hline & Density $\left(\mathrm{kg} / \mathrm{m}^{3}\right)$ & Elastic modulus $(\mathrm{MPa})$ & Poisson's ratio & Orthodontic force $(\mathrm{N})$ \\
\hline EA & $1,269( \pm 2.4)$ & $731.46( \pm 30.37)$ & $0.402( \pm 0.005)$ & 3.2344 \\
DU & $1,270.4( \pm 2.8)$ & $710.51( \pm 23.64)$ & $0.394( \pm 0.003)$ & 3.2275 \\
ER & $1,265( \pm 1.0)$ & $689.78( \pm 17.01)$ & $0.406( \pm 0.005)$ & 3.2216 \\
EC & $* 894.2( \pm 1.4)$ & $* 498.97( \pm 26.93)$ & $0.402( \pm 0.006)$ & 3.153 \\
\hline
\end{tabular}

One-way ANOVA, Scheffe's test $\left({ }^{*} p<0.05\right), n=5$, ( ): S.D.
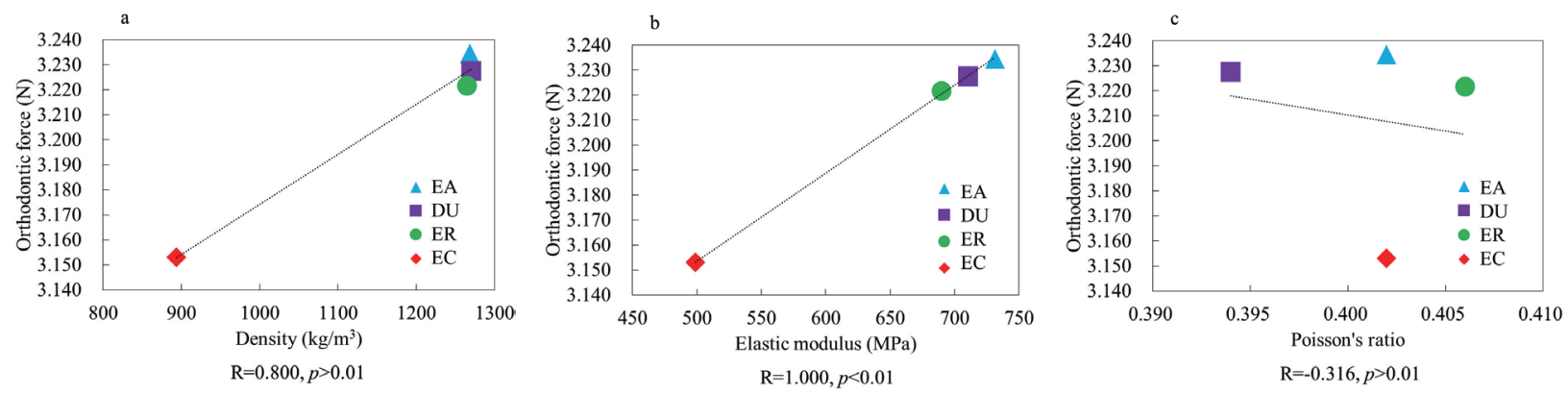

Fig. 4 Correlation between the physical properties and orthodontic force: a) density, b) elastic modulus, and c) Poisson's ratio.

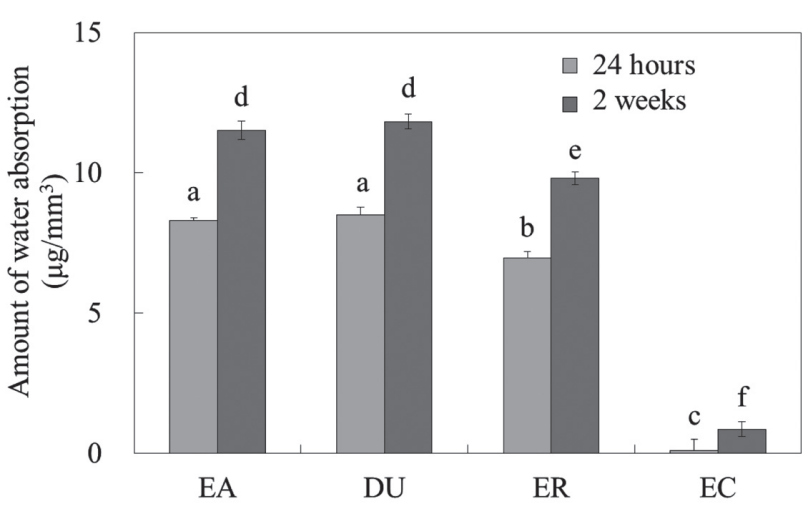

Fig. 5 Water absorption of EA, DU, ER, and EC after 24 $\mathrm{h}$ and 2 weeks of water immersion.

Two-way ANOVA, Bonferroni test $(p<0.05), n=5$, and error bars indicate S.D. Means with the same letter are not significantly different.

\section{Constant strain loading test}

The elastic moduli of the thermoplastic materials immersed in distilled water at $37^{\circ} \mathrm{C}$ for $24 \mathrm{~h}$ without strain were $705.8 \pm 13.95 \mathrm{MPa}$ for EA, $684.8 \pm 22.50 \mathrm{MPa}$ for DU, 726.3 $\pm 31.13 \mathrm{MPa}$ for $\mathrm{ER}$, and $366.0 \pm 54.19 \mathrm{MPa}$ for EC (Fig. 6). After immersion in distilled water for 2 weeks without strain, the elastic moduli increased to $783.6 \pm 13.76 \mathrm{MPa}$ for $\mathrm{EA}, 724.1 \pm 38.35 \mathrm{MPa}$ for $\mathrm{DU}$, and $782.8 \pm 35.67 \mathrm{MPa}$ for ER, and decreased slightly to $351.5 \pm 27.81 \mathrm{MPa}$ for EC (Fig. 6). The elastic moduli of the materials when immersed in distilled water for 2 weeks with $1 \%$ constant strain were $598.7 \pm 74.79 \mathrm{MPa}$ for $\mathrm{EA}, 641.4 \pm 34.49 \mathrm{MPa}$ for DU, $619.5 \pm 75.81 \mathrm{MPa}$ for

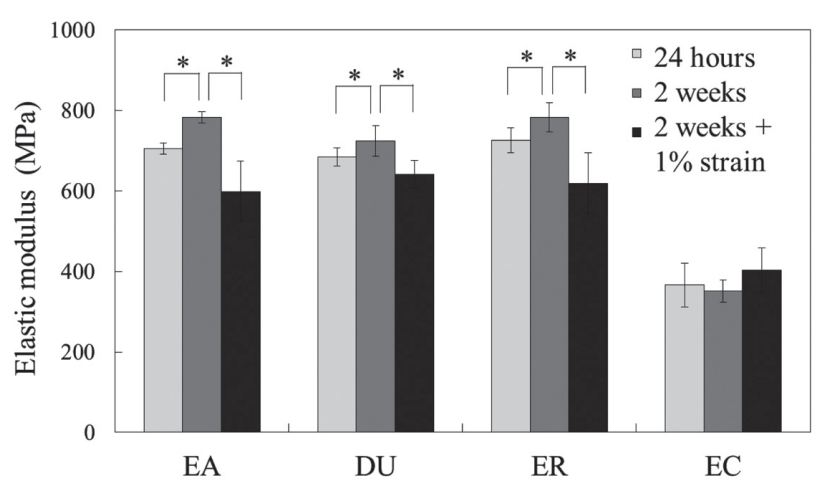

Fig. 6 Elastic modulus of EA, DU, ER, and EC after $24 \mathrm{~h}$ and 2 weeks water immersion and 2 weeks water immersion with $1 \%$ strain loading. Student's $t$-test $\left({ }^{*} p<0.05\right), n=5$, and error bars indicate S.D.

ER, and 403.6 $\pm 55.17 \mathrm{MPa}$ for EC (Fig. 6). A significant reduction of elastic modulus was observed in EA, DU, and ER by applying a constant strain. However, no change in elastic modulus was found in EC.

\section{XRD analysis}

The XRD patterns of each material are shown in Fig. 7. Diffraction patterns indicated that EA, DU, and ER were amorphous phases while EC was a crystalline polymer.

\section{FT-IR analysis}

The infrared absorption spectrum obtained by FT-IR analysis of EA (Fig. 8a), DU (Fig. 8b), and ER (Fig. 8c) showed $\mathrm{C}=\mathrm{O}$ stretching vibration at about $1,727 \mathrm{~cm}^{-1}$, 


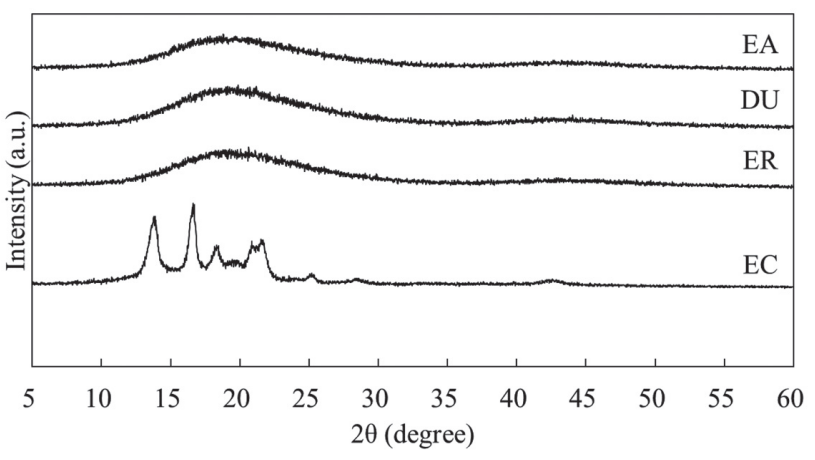

Fig. 7 X-ray diffraction pattern of EA, DU, ER, and EC.
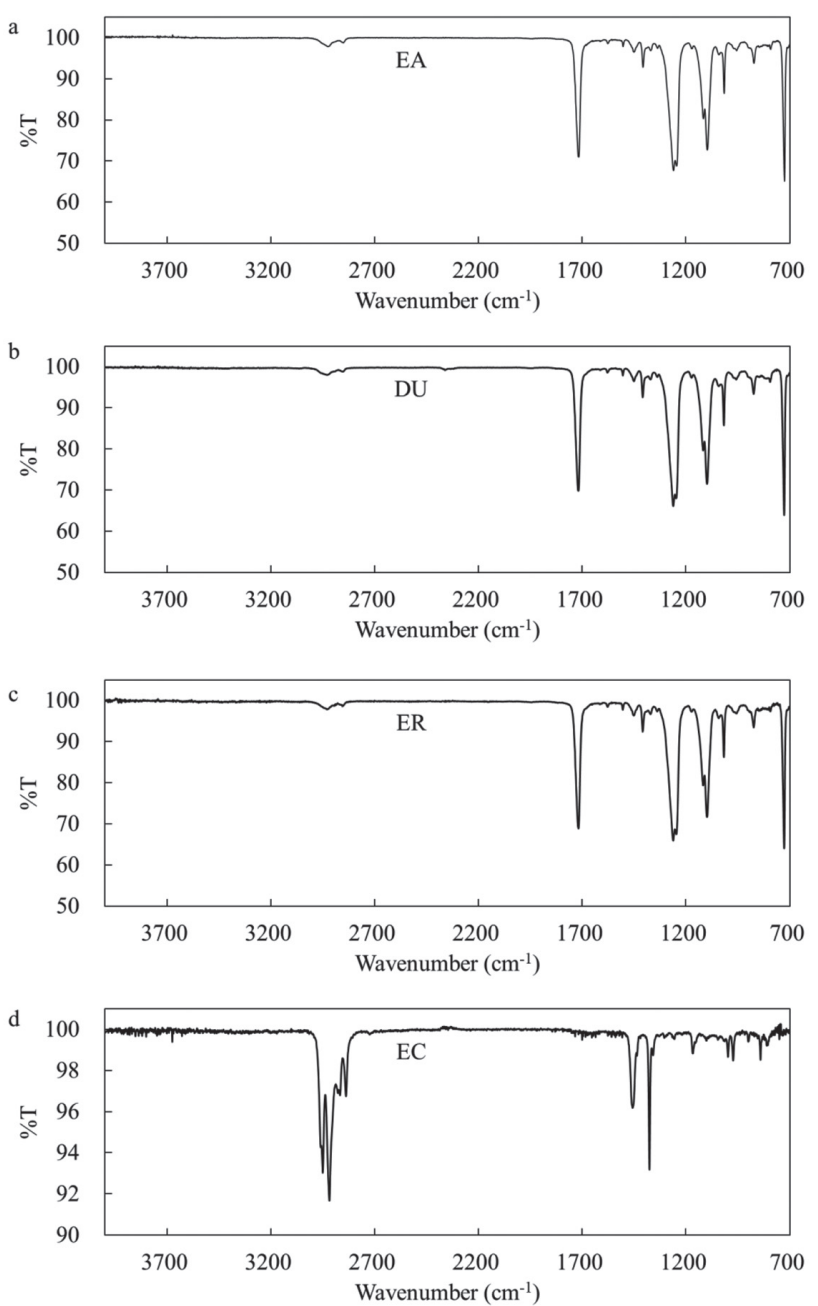

Fig. 8 Infrared absorption spectrum for a) EA, b) DU, c) ER, and d) EC.

C-O stretching vibration at about $1,263 \mathrm{~cm}^{-1}, \mathrm{C}(\mathrm{O})-\mathrm{O}$ stretching vibration and benzene ring vibration at about $1,126 \mathrm{~cm}^{-1}$, and $-\mathrm{CH}$ out-of-plane bending vibration at about $727 \mathrm{~cm}^{-1}$, while the infrared absorption spectrum obtained by FT-IR analysis of EC (Fig. 8d) showed $\mathrm{CH}$ stretching vibration and $\mathrm{CH}$ bending vibration.

\section{DISCUSSION}

Thermoplastic materials composed of polyethylene terephthalate glycol (PETG) such as DU and ER, polyurethane (PU), and polyethylene terephthalate are used as aligners ${ }^{4,19)}$. Moreover, new thermoplastic materials such as a composite of PETG, PU, and polycarbonate at an original compounding ratio ${ }^{4)}$ and PU with a shape memory function ${ }^{30)}$ have been developed ${ }^{4,20)}$. To evaluate the physical properties of these materials, water absorption ${ }^{4,17)}$, tensile ${ }^{4,17)}$, threepoint bending ${ }^{18-20)}$, and stress relaxation ${ }^{4,16)}$ tests have been carried out. However, there has been no study to investigate the relationship between the behavior of the orthodontic force exerted by the aligner and the change in the physical properties of the thermoplastic materials over time. In this study, a physical property suitable for evaluation of orthodontic force was identified from analysis of commercial thermoplastic materials. The influence of water absorption and strain on the elastic modulus reflected the clinical use of an aligner with these materials for 2 weeks.

Among the various material properties of thermoplastic materials, density, elastic modulus, and Poisson's ratio were selected as possible physical properties that would be related to the expression of orthodontic force. After these physical properties of commercial thermoplastic materials EA, DU, ER, and EC were measured, 3D FEA was conducted using the obtained values to identify the physical properties that would be suitable for the evaluation of orthodontic force exerted by aligners. A significant correlation was found between the elastic modulus and the orthodontic force for all four thermoplastic materials, suggesting that the measurement of the elastic modulus is suitable for comparing orthodontic forces exerted by aligners. Although the in silico model designed in this study does not completely reflect the orthodontic force in the oral cavity because the thickness of the periodontal ligament and the biological properties of the surrounding bone were not precisely simulated, the elastic modulus should be one of the primary indexes to compare thermoplastic materials.

Because the elastic modulus of the thermoplastic materials was significantly correlated with the orthodontic force, the influence of water absorption and strain on the elastic modulus was investigated to clarify the factors that affect the orthodontic force expressed by the thermoplastic materials. EC had a significantly smaller water absorption than EA, DU, and ER. XRD analysis revealed that EA, DU, and ER had an amorphous phase while EC had a crystalline phase. Crystalline plastic has low water absorption, therefore the low water absorption of EC was likely due to its high crystallinity. From the FT-IR spectrum, similar molecular structures were observed for EA, DU, and ER. EA is constructed by a polycondensate of a polycarboxylic acid and a polyalcohol. polyethylene terephthalate (PET), Polybutylene terephthalate, and PETG (a composition of DU and ER) are also included in the 
definition of polyester (PES). The molecular structures of polymers classified into these PES are similar, and the FT-IR spectrums of EA, DU, and ER were similar, suggesting that the composition of EA could be PETG.

The elastic moduli of EA, DU, and ER were significantly increased by immersion in distilled water for 2 weeks without strain, which might be a result of the increased volume due to water absorption and the swelling due to water molecules penetrating the molecular chains. The increased elastic modulus of EA as well as DU and ER confirmed that the composition of EA is PETG. After immersion in distilled water for 2 weeks with a constant strain of $1 \%$, the elastic moduli of EA, DU, and ER decreased. PET, as one of the amorphous plastics, has irregularly intertwined molecular chains that are easily rearranged after applying strain. EA, DU, and ER are composed of PETG, which is the plastic in which a part of ethylene glycol of PET is substituted with cyclohexane dimethanol ${ }^{31)}$. Since the molecular structure of PETG is similar to PET, the elastic modulus of PET decreased for a similar reason. Unlike EA, DU, and ER, the change in elastic modulus due to water absorption was not observed for EC. The same elastic modulus was measured after water immersion for 2 weeks with and without strain. In EC, which is composed of Polypropylene, regularly and irregularly arranged parts were mixed in the molecular chains with a helical structure. Therefore, the absolute amount of molecular chains enabling those rearrangements is small even in the strain loading, confirming that EC was less affected by strain. Reflecting these properties of $\mathrm{PP}$, a crystalline plastic EC may have a constant elastic modulus under constant strain loading.

However, a large amount of wear in abrasion testing has been reported for EC compared with EA and other polyethylene copolymer thermoplastic materials, and it is easy to perforate and crack while using EC as an aligner $^{32,33)}$. Deformation, cracking, and deposition of calcium phosphate on the aligner surface have been observed after using the aligner made from PU after 2 weeks in the oral cavity ${ }^{34,35)}$. In addition, an increase in Vickers hardness due to changes in crystallinity has been reported ${ }^{35}$. In the intraoral environment, changes in the elastic modulus as confirmed in this study. Investigations such as abrasion tests for clinical applications will be required. It is also assumed that placing the aligner on the teeth and removing it from the teeth temporarily causes large strain in the aligner, but the effect on the physical properties of the aligner and the orthodontic force are unknown. Further studies should be performed to quantify these effects.

Investigation of novel thermoplastic materials with a crystalline phase and lower elastic modulus than EC is underway. The aligner prototype placed on a dentition model with a force sensor will be tested by measuring the change in orthodontic force over 2 weeks.

\section{CONCLUSION}

An in silico 3D FEA reflecting the physical properties of commercially available thermoplastic showed that the elastic modulus can be used to evaluate the orthodontic force.

A crystalline thermoplastic EC with low water absorption demonstrated a stable elastic modulus even under strain in a wet environment, suggesting there are advantages of using EC as the material in orthodontic aligners.

\section{ACKNOWLEDGMENTS}

We thank Melissa GIBBONS, PhD, from Edanz Group (www.edanzediting.com/ac) for editing a draft of this manuscript.

\section{CONFLICT OF INTEREST}

None

\section{REFERENCES}

1) Ponitz RJ. Invisible retainers. Am J Orthod 1971; 59: 266 272.

2) McNamara JA, Kramer KL, Juenker JP. Invisible retainers. J Clin Orthod 1985; 19: 570-578.

3) Sheridan JJ. The Essix bracket choice appliance. J Clin Orthod 1996; 30: 203-205.

4) Zhang N, Bai Y, Ding X, Zhang Y. Preparation and characterization of thermoplastic materials for invisible orthodontics. Dent Mater J 2011; 30: 954-959.

5) Fernandez Sanchez J, Pernia Ramirez I, Martin Alonso J. Osamu active retainer for correction of mild relapse. J Clin Orthod 1998; 32: 26-28.

6) Boyd RL MR, Vlaskalic V. The Invisalign system in adult orthodontics: mild crowding and space closure cases. J Clin Orthod 2000; 34: 203-212.

7) Wong BH. Invisalign A to Z. Am J Orthod Dentofacial Orthop 2002; 121: 540-541.

8) Tuncay OC. The Invisalign system. Quintessence Int; 2006. p. 77-90.

9) Kravitz ND, Kusnoto B, Agran B, Viana G. Influence of attachments and interproximal reduction on the accuracy of canine rotation with Invisalign. A prospective clinical study. Angle Orthod 2008; 78: 682-687.

10) Zawawi KH. Orthodontic treatment of a mandibular incisor extraction case with invisalign. Case Rep Dent 2014; 2014: 657.

11) Frongia G, Castroflorio T. Correction of severe tooth rotations using clear aligners: a case report. Aust Orthod J 2012; 28: 245-249.

12) Schupp W, Haubrich J, Neumann I. Treatment of anterior open bite with the Invisalign system. J Clin Orthod 2010; 44: 501-507.

13) Giancotti A, Mampieri G, Greco M. Correction of deep bite in adults using the Invisalign system. J Clin Orthod 2008; 42: 719-726.

14) Kim TW, Echarri P. Clear aligner: an efficient, esthetic, and comfortable option for an adult patient. World J Orthod 2007; 8: $13-18$.

15) Graber TM, Swain BF. Orthodontics, current principles and techniques. St. Louis: C.V. Mosby Co.; 1985. p. 639-667.

16) Fang D, Zhang N, Chen H, Bai Y. Dynamic stress relaxation of orthodontic thermoplastic materials in a simulated oral environment. Dent Mater J 2013; 32: 946-951.

17) Ryokawa HMY, Fujishima A, Miyazaki T, Maki K. The mechanical properties of dental thermoplastic materials in a 
simulated intraoral environment. Orthod Waves 2006; 65: 6472 .

18) Kwon JS, Lee YK, Lim BS, Lim YK. Force delivery properties of thermoplastic orthodontic materials. Am J Orthod Dentofacial Orthop 2008; 133: 228-234.

19) Lombardo L, Martines E, Mazzanti V, Arreghini A, Mollica F, Siciliani G. Stress relaxation properties of four orthodontic aligner materials: A 24-hour in vitro study. Angle Orthod 2017; 87: 11-18.

20) Iijima M, Kohda N, Kawaguchi K, Muguruma T, Ohta M, Naganishi A, et al. Effects of temperature changes and stress loading on the mechanical and shape memory properties of thermoplastic materials with different glass transition behaviours and crystal structures. Eur J Orthod 2015; 37: 665-670.

21) Li X, Ren C, Wang Z, Zhao P, Wang H, Bai Y. Changes in force associated with the amount of aligner activation and lingual bodily movement of the maxillary central incisor. Korean $\mathrm{J}$ Orthod 2016; 46: 65-72.

22) Barbagallo LJ, Shen G, Jones AS, Swain MV, Petocz P, Darendeliler MA. A novel pressure film approach for determining the force imparted by clear removable thermoplastic appliances. Ann Biomed Eng 2008; 36: 335341.

23) Hahn W, Fialka-Fricke J, Dathe H, Fricke-Zech S, Zapf A, Gruber R, et al. Initial forces generated by three types of thermoplastic appliances on an upper central incisor during tipping. Eur J Orthod 2009; 31: 625-631.

24) Elkholy F, Panchaphongsaphak T, Kilic F, Schmidt F, Lapatki BG. Forces and moments delivered by PET-G aligners to an upper central incisor for labial and palatal translation. $\mathrm{J}$ Orofac Orthop 2015; 76: 460-475.

25) Kohda N, Iijima M, Muguruma T, Brantley WA, Ahluwalia KS, Mizoguchi I. Effects of mechanical properties of thermoplastic materials on the initial force of thermoplastic appliances. Angle Orthod 2013; 83: 476-483.

26) ISO527-2:2012. Plastics -Determination of tensile properties-Part 2: Test conditions for moulding and extrusion plastics. International Organization for Standardization; 2012.

27) ISO527-3:1995. Plastics -Determination of tensile properties - Part 3: Test conditions for films and sheets. International Organization for Standardization; 1995.

28) Mitsuhashi N, Fujieda K, Tamura T, Kawamoto S, Takagi T, Okubo K. BodyParts3D: 3D structure database for anatomical concepts. Nucleic Acids Res 2009; 37: D782-785.

29) ISO4049:2009. Dentistry -Polymer-based restorative materials. International Organization for Standardization; 2009.

30) Sokolowski W, Metcalfe A, Hayashi S, Yahia L, Raymond J. Medical applications of shape memory polymers. Biomed Mater 2007; 2: S23-27.

31) Easter $^{\mathrm{TM}}$ PETG copolyester. Material Safety Data Sheets; 2014.

32) Raja TA, Littlewood SJ, Munyombwe T, Bubb NL. Wear resistance of four types of vacuum-formed retainer materials: a laboratory study. Angle Orthod 2014; 84: 656-664.

33) Gardner GD, Dunn WJ, Taloumis L. Wear comparison of thermoplastic materials used for orthodontic retainers. Am J Orthod Dentofacial Orthop 2003; 124: 294-297.

34) Eliades T, Bourauel C. Intraoral aging of orthodontic materials: the picture we miss and its clinical relevance. Am J Orthod Dentofacial Orthop 2005; 127: 403-412.

35) Schuster S, Eliades G, Zinelis S, Eliades T, Bradley TG. Structural conformation and leaching from in vitro aged and retrieved Invisalign appliances. Am J Orthod Dentofacial Orthop 2004; 126: 725-728. 